\title{
ESTUDO COMPARATIVO DE TÉCNICAS FOTOQUÍMICAS APLICADOS AO TRATAMENTO DE EFLUENTES DO BENEFICIAMENTO DA CASTANHA DE CAJU
}

\author{
C. E. M. JERÔNIMO ${ }^{1}$, H. G FERNANDES ${ }^{2}$, H. N. S. MELO ${ }^{3}$ e J. F. SOUSA ${ }^{4}$ \\ ${ }^{1}$ Universidade Potiguar - UnP \\ 2,3,4 Universidade Federal do Rio Grande do Norte - DEQ. \\ c_enrique@hotmail.com ${ }^{1}$, hermano_eq@yahoo.com.br ${ }^{2}$, henio@eq.ufrn.br ${ }^{3}$, joao@eq.ufrn.br ${ }^{4}$
}

Artigo submetido em março/2012 e aceito em fevereiro/2014

\section{RESUMO}

O beneficiamento da castanha de caju é uma das atividades industriais de maior importância nos Estados do Nordeste Brasileiro. Em vista dessa intensa atividade produtiva, essas indústrias são grandes geradoras de efluentes líquidos, cujas características ainda são pouco conhecidas devido à pequena quantidade de trabalhos científicos realizados na área. Entretanto, os processos "convencionais" continuam sendo maciçamente adotados, mesmo em situações em que a sua eficiência é discutível. O presente trabalho objetivou estudar a potencialidade de processos oxidativos avançados (sistema UV/H2O2, Fenton e foto-Fenton) de maneira isolada e/ou combinada. Os resultados apontam para uma relação de efluente/ $\mathrm{H} 2 \mathrm{O} 2$ na ordem de $20 \%$, como sendo os mais indicados nas diferentes técnicas. Além disso, verificou-se que a técnica de UV-Peróxido se mostrou a mais adequada para o tratamento desse efluente.

PALAVRAS-CHAVE: Tratamento de efluentes, Degradação fotoquímica; Processo UV-peróxido

\section{PHOTOCHEMICAL COMPARATIVE STUDY OF TECHNIQUES APPLIED TO WASTEWATER TREATMENT OF IMPROVEMENT CASHEW NUTS}

\begin{abstract}
The processing of cashew nuts is one of the most important industrial activities in the states of Northeastern Brazil. In view of intense productive activity, these industries are major generators of wastewater, whose characteristics are still poorly known due to the small amount of scientific work in the area. However, the "conventional" processes remain overwhelmingly adopted, even in situations in which their efficiency is questionable. The present work aimed
\end{abstract}

to study the potential of advanced oxidation processes (UV/H2O2, Fenton and Photo-Fenton system) in an isolated and/or combined manner. The results pointed towards a relation between effluent/H2O2 in a $20 \%$ order as the most indicated in different technics. Furthermore, it was found that the technique of UVperoxide proved to be the most suitable for the treatment of the effluent.

KEYWORDS: Effluent treatment, photochemical degradation, UV-peroxide process. 


\section{INTRODUÇÃO}

Os processos de oxidação avançados são de grande interesse para o tratamento de efluentes, águas superficiais e subterrâneas contaminadas e para a produção com elevado grau de pureza. Os resultados de trabalhos experimentais com diferentes substratos e amostras de águas contaminadas foram tão interessantes que parcerias foram estabelecidas com indústrias em projetos de ampliação de escala. Porém, para o desenvolvimento de tais técnicas, é muito importante a escolha do processo, a construção e modelo da unidade fotoquímica, bem como a sua otimização (Braun e Oliveros, 1997).

Apesar dos processos de oxidação avançados (POAs) serem constituídos por diferentes sistemas reativos, todos têm a mesma característica química: a produção de radicais hidroxilas (HO•) por um oxidante, com exceção da fotólise da água com Ultra Violeta (Braun e Oliveros, 1997). Os radicais $\mathrm{OH}$ são espécies muito reativas que atacam a maior parte das moléculas orgânicas com uma taxa constante da ordem de 106-109M-1s-1. Estes processos também são caracterizados pela baixa seletividade do ataque, o que é uma característica muito importante para um oxidante utilizado no tratamento de efluentes. A versatilidade dos POAs é realçada pelo fato de existirem diversas possibilidades para a produção dos radicais hidroxilas, o que permite a escolha do método mais adequado de acordo com o tratamento necessário (Andreozzi et al., 1999).

A aplicação adequada de um POA deve considerar o uso de reagentes caros, como, por exemplo, $\mathrm{H}_{2} \mathrm{O}_{2}$ e/ou $\mathrm{O}_{3}$, e, por isso, fica claro que os mesmos nunca deveriam substituir os tratamentos biológicos, quando estes forem possíveis, já que são muito mais econômicos. Os POAs podem complementar os tratamentos biológicos na degradação oxidativa de substâncias tóxicas que entram ou deixam o estágio biológico (Andreozzi et al., 1999).

Dentre as técnicas utilizadas neste trabalho para o tratamento oxidativo de efluentes destaca-se o emprego das técnicas derivadas da utilização do peróxido de hidrogênio. Essas técnicas consistem na liberação dos radicais hidroxilas mediante o emprego da radiação ultravioleta de forma direta (UV-Peróxido), a catalisação do processo mediante íons de ferro (processo de Fenton) e a combinação das duas técnicas pelo processo de Foto-Fenton.

O estudo comparativo deste trabalho foi realizado com um efluente de baixa biodegradabilidade, oriundo do processo de beneficiamento da castanha de caju. Esse efluente é rico em substâncias fenólicas, o que concede a este um risco inerente bastante elevado com uma possível disposição inadequada desse material em algum corpo receptor.

A literatura registra poucos estudos na especificação de técnicas para o tratamento de tal efluente, ficando-se, os registros encontrados, concentrados na aplicação de fungos para tal tratamento.

Neste trabalho, expõem-se os resultados obtidos em escala experimental, dos ensaios realizados mediante planejamentos fatoriais, que buscaram a comparação entre as técnicas estudadas, frente a sua cinética de degradação e consequentemente parâmetros de eficiência e de projetos para sistemas em escalas reais. 


\section{MATERIAIS E MÉTODOS}

Os ensaios foram realizados em um reator fotoquímico anular com um volume útil de líquido de 4,0 L. A fonte de radiação usada é uma lâmpada de vapor de mercúrio (450 Watts) de média pressão, posicionada no eixo longitudinal do reator, no interior de uma camisa de borossilicato, por onde circula água com a finalidade de resfriar a lâmpada. 0 tipo do material utilizado determina a faixa de comprimento de onda, no caso do borossilicato, só atravessam os comprimentos de onda do UV mais próximo do visível (400-700 nm), o que pode ser importante na verificação de um possível uso da radiação natural (proveniente do sol) como fonte de fótons para o processo Foto-Fenton. Na Figura 1 é apresentado o esquema do reator.

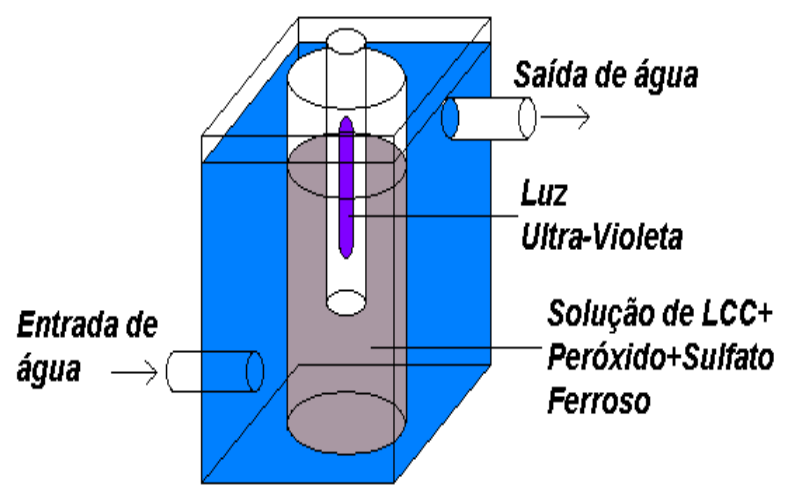

Figura 1: Esquema do Reator Fotoquímico.

O fluxo de água de arrefecimento foi controlado, de forma a estabelecer uma temperatura de operação do sistema de aproximadamente $37^{\circ} \mathrm{C}$.

Os níveis operacionais, realizados em duplicata, foram estabelecidos como sendo os apresentados na Tabela 1.

Tabela 1: Planejamento dos ensaios Foto-Fenton

\begin{tabular}{|c|c|c|c|}
\hline Ensaio & $\begin{array}{c}\text { Volume do Efluente } \\
\text { Sintético } \\
(\mathbf{m L})\end{array}$ & $\begin{array}{c}\text { Volume de Peróxido } \\
(\mathbf{m L})\end{array}$ & $\begin{array}{c}\text { Dosagem de } \\
\text { FeSO } \mathbf{~ ( g ) ~}\end{array}$ \\
\hline $\mathbf{1}$ & 2800 & 1200 & 1,12 \\
\hline $\mathbf{2}$ & 2920 & 1080 & 1,00 \\
\hline $\mathbf{3}$ & 2650 & 1350 & 1,23 \\
\hline $\mathbf{4}$ & 3040 & 960 & 1,23 \\
\hline $\mathbf{5}$ & 2530 & 1470 & 1,00 \\
\hline
\end{tabular}

Os ensaios de Fenton foram operados com a Lâmpada de Mercúrio desligada, e com a mesma relação de Ferro e Peróxido de hidrogênio utilizado nos testes fotoquímicos.

O monitoramento dos experimentos foi estabelecido com a medição da Demanda Química de Oxigênio (DQO), mediante a técnica de refluxo-espectrofotométrico. Além disso, o consumo de peróxido de hidrogênio e a turbidez do sistema, também, foi registrado em intervalos regulares de tempo. 
Os efluentes foram coletados em uma indústria de castanha, após a liberação para o sistema de tratamento físico da unidade, de forma homogênea, e oriundos dos processos de lavagem e umidificação da castanha.

Os parâmetros avaliados foram o volume de efluente e de peróxido de hidrogênio são apresentado na Tabela 1. O tempo total de tratamento foi estabelecido em $240 \mathrm{~min}$.

\section{RESULTADOS OBTIDOS}

Considerando os dados cinéticos obtidos na Figura 2, observa-se que o efeito é insignificante para a variação do volume de efluente e positivo em função da concentração de oxidante.

Os resultados mostrados, especificamente o que diz respeito à diminuição da eficiência do processo com o aumento da concentração de peróxido, podem ser explicados pelo caráter sequestrante (scanvenger) de radicais hidroxila (equações 1 e 2) apresentado pelo peróxido e ainda pelo processo de recombinação de radicais, quando gerados em excesso (equação 3 ).

$$
\begin{array}{ll}
\mathrm{H}_{2} \mathrm{O}_{2}+\mathrm{OH} \bullet \rightarrow \mathrm{HO}_{2} \bullet+\mathrm{H}_{2} \mathrm{O} & \text { equação (1) } \\
\mathrm{HO}_{2} \bullet+\mathrm{H}_{2} \mathrm{O} \rightarrow \mathrm{H}_{2} \mathrm{O}+\mathrm{O}_{2} & \text { equação (2) } \\
\mathrm{OH} \bullet+. \mathrm{OH} \bullet \rightarrow \mathrm{H}_{2} \mathrm{O}_{2} & \text { equação (3) }
\end{array}
$$

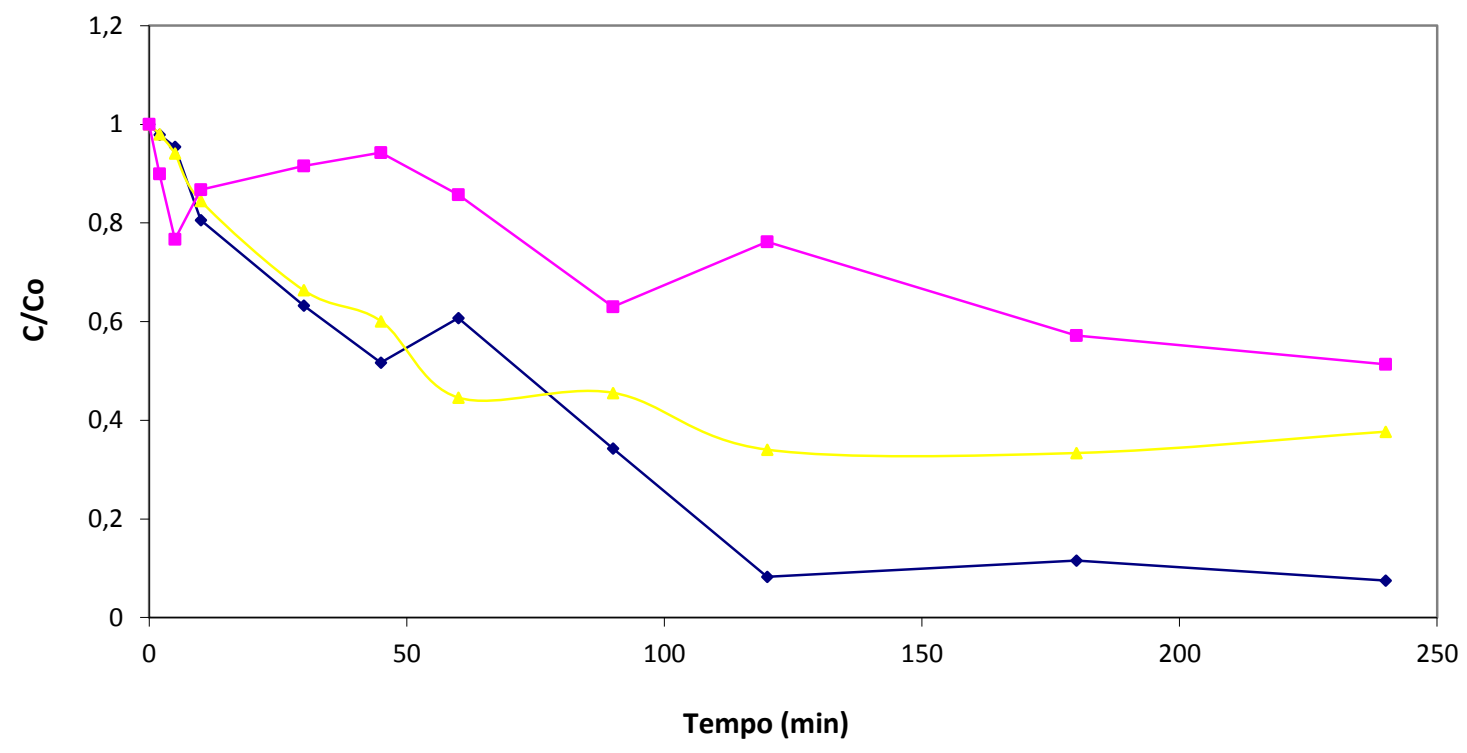

Figura 2: Frações residuais de LCC em UV-Peróxido nos ensaios $(\diamond) 1,(\Delta) 3,(\square) 5, C 0=0,8 g / L$, de acordo com o planejamento da Tabela 1.

A Figura 2 indica que as melhores condições de degradação estão representados pelo ensaio 1, volume de efluente igual a $2800 \mathrm{~mL}$ e de peróxido de hidrogênio igual a $1200 \mathrm{~mL}$. Os resultados indicam que tratamentos de 120 minutos permitem uma significativa diminuição da fração residual do efluente em questão. Para os outros ensaios verifica-se uma eficiência global limitada, provavelmente por conta do rápido consumo de peróxido de hidrogênio. 
No processo UV/ $\mathrm{H}_{2} \mathrm{O}_{2}$ a solução contendo o efluente e $\mathrm{H}_{2} \mathrm{O}_{2}$ é irradiada com luz UV de comprimento de onda menor que $280 \mathrm{~nm}$, causando a homólise da molécula de peróxido e gerando radicais hidroxila que podem oxidar o composto orgânico.

Uma vez que o sistema UV/H2O2 é reconhecidamente eficiente para degradar inúmeros substratos orgânicos, inclusive aqueles reconhecidamente recalcitrantes, como fenol, os resultados obtidos para o sistema permitem classificar o efluente de beneficiamento da castanha de caju como sendo altamente indicado para tratamento com UV-Peróxido.

As concentrações de íons ferrosos e peróxido de hidrogênio foram otimizadas por planejamento fatorial (Tabela 1), em tempos de reação de 240 minutos. A reação de Fenton deve ser processada em pH ácido, de maneira a se evitar a precipitação de óxidos férricos e é universalmente aceito que as formas químicas em que o ferro se encontra quando os valores de pH estão próximos de 4 favorecem o processo em questão. Por esses motivos, todos os ensaios foram realizados em $\mathrm{pH} 3$.

Os resultados preliminares obtidos na Figura 3 indicam um feito negativo da concentração do ferro e um efeito positivo da concentração de peróxido de hidrogênio, o que define o experimento 1 como a melhor condição para degradação do efluente em estudo. Observa-se também que as variáveis concentração de ferro e de H2O2 tem uma correlação baixa, pois os efeitos de segunda ordem são desprezíveis.

A indicação do ponto 1 como melhor condição experimental (ver Figura 3) está de acordo com a teoria, visto que o excesso de ferro costuma diminuir a eficiência do processo, em razão da captura de radicais hidroxila (íons ferrosos atuam com scavengers de radicais). Nota-se também que o excesso de ferro pode resultar na formação de complexos ferro-peróxidos, que levam à formação de radicais hidroperoxila, de reatividade menor que o radical hidroxila.

O estudo cinético de degradação foi realizado na forma em que o processo Fenton pode ser aplicado. Isto é, na ausência de qualquer fonte de irradiação artificial.

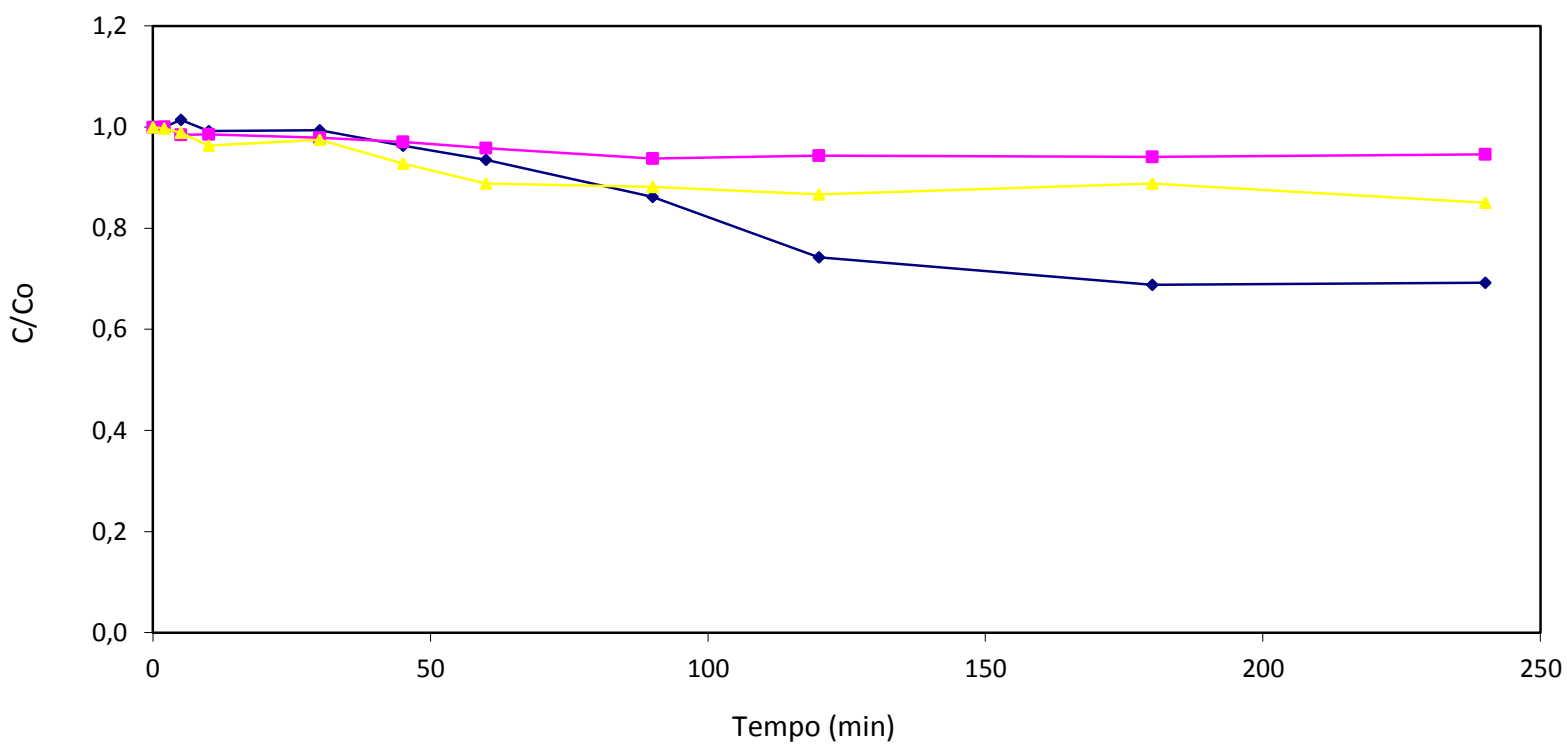

Figura 3: Frações residuais de LCC em Fenton nos ensaios $(\bullet) 1,(\Delta) 3,(\square) 5, C 0=0,8 g / L$, de acordo com 0 planejamento da Tabela 1. 
No processo Fenton poucas diferenças foram observadas no que diz respeito a remoção de matéria orgânica pelo que é observado na Figura 3. Reduções de DQO da ordem de 30\% foram registradas, em tempos de reação de 120 minutos. É necessário destacar que a estabilização observada no processo Fenton, a partir de 80 minutos de reação, pode sugerir o esgotamento dos íons ferrosos. Na ausência de radiação, íons férricos se acumulam, cessando a atividade da reação.

O mecanismo da reação Fenton, proposto por Harber e Weiss (1934), baseia-se numa reação de redução simples onde o $\mathrm{Fe}^{+2}$ é oxidado a $\mathrm{Fe}^{+3}$ e o peróxido é reduzido ao íon hidroxila, gerando ao mesmo tempo o radical hidroxila, de acordo com a seguinte reação

$$
\mathrm{Fe}^{+2}+\mathrm{H}_{2} \mathrm{O}_{2} \rightarrow \mathrm{Fe}^{+3}+\mathrm{OH} \bullet+\mathrm{OH}-\quad \text { equação (4) }
$$

O íon férrico $\left(\mathrm{Fe}^{+3}\right)$ prduzido pela equação (4) pode ser reduzido a $\mathrm{Fe}^{+2}$ (Giroto, 2002) pela seguinte reação:

$$
\mathrm{Fe}^{+3}+\mathrm{H}_{2} \mathrm{O}_{2} \rightarrow \mathrm{Fe}^{+2}+\mathrm{H}^{+}+\mathrm{HO}_{2} \bullet
$$

Esta etapa é mais lenta e acaba sendo o passo determinante da cinética global.

A reação Fenton é eficiente para a remoção de poluentes orgânicos, mas requer quantidades estequiométricas de íon ferroso, $\mathrm{Fe}^{+2}$ (Giroto, 2002). Esta reação é retardada após a conversão completa de $\mathrm{Fe}^{+2}$ a $\mathrm{Fe}^{+3}$.

A reação de Fenton em presença de luz UV e/ou visível aumenta a taxa de produção de radicais hidroxila, acelerando a taxa de degradação de poluentes orgânicos (Rosseti, Albizzati \& Alfano, 2002). Neste caso a reação passa a ser designada de foto-Fenton ou Fenton fotoassistida (Giroto, 2002), intensificando a degradação de poluentes orgânicos. Isto ocorre porque os íons férricos produzidos na Equação (4), são reduzidos, por fotólise, a íons ferrosos, de acordo com a equação (6) (Henle, Luo \& Linn, 1996).

$$
\mathrm{Fe}^{+3}+\mathrm{H} 2 \mathrm{O} \stackrel{h v}{\longrightarrow} \mathrm{Fe}^{+2}+\mathrm{OH} \bullet+\mathrm{H}^{+} \text {equação (6) }
$$

Esta reação é mais rápida e a redução dos íons férricos a ferrosos passa a não ser o passo determinante da reação (Nascimento, 2002), promovendo uma aceleração no processo.

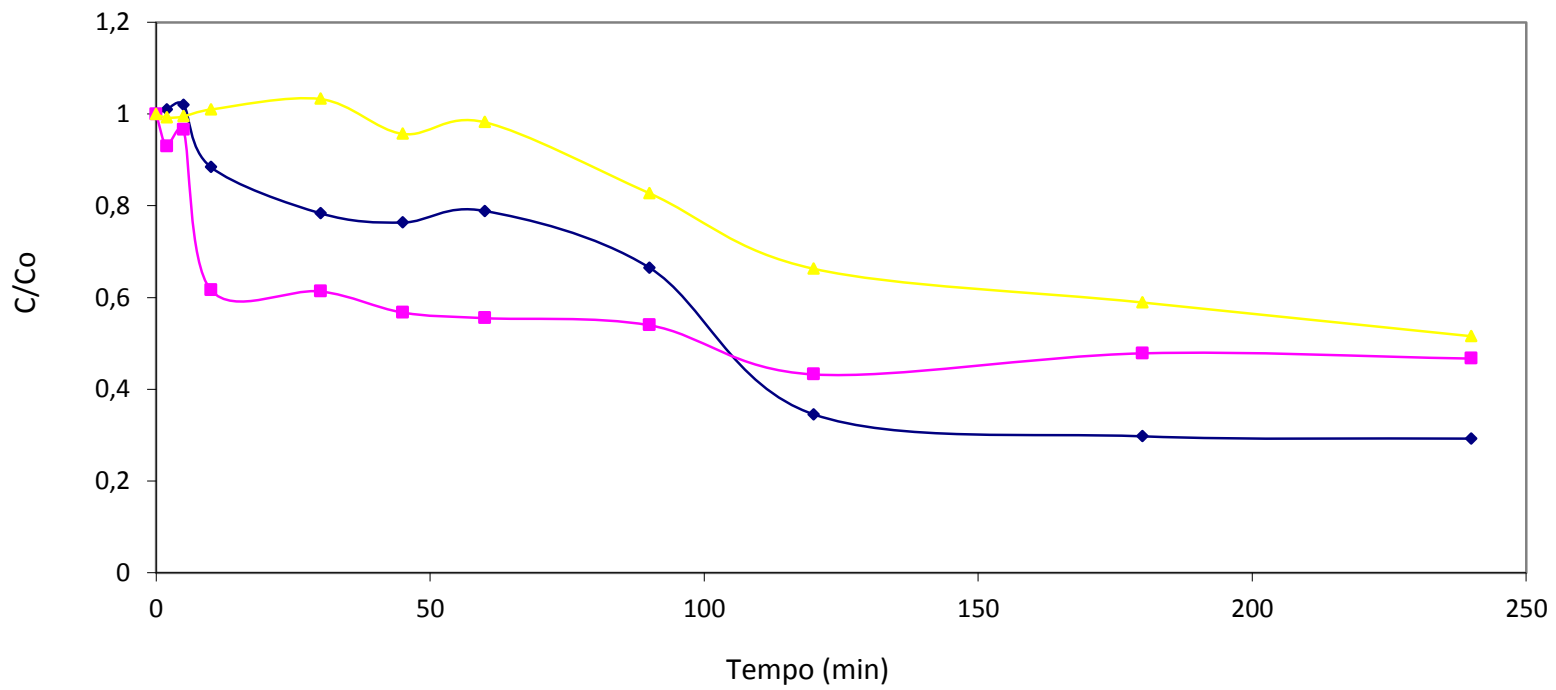


Figura 4: Frações residuais de LCC em foto-Fenton nos ensaios $(\diamond) 1,(\square) 3,(\Delta) 5, C_{0}=0,8 g / L$, de acordo com o planejamento da Tabela 1.

A Figura 4 acima indica que as melhores condições de degradação para o processo fotoFenton estão representados pelo ensaio 1, volume de efluente igual a $2800 \mathrm{~mL}$, de peróxido de hidrogênio igual a $1200 \mathrm{~mL}$ e de Fe igual a 1,12 g. Os resultados indicam que tratamentos de 120 minutos permitem uma significativa diminuição da fração residual do efluente em questão. Para os outros ensaios verifica-se uma eficiência global limitada, por razões justificadas acima.

Foram realizados testes com o objetivo de comparar a cinética de degradação do POA pelos processos de $\mathrm{UV} / \mathrm{H}_{2} \mathrm{O}_{2}$, Fenton e foto-Fenton. A Figura 5 mostra as curvas da comparação entre estes três processos.

$\mathrm{O}$ ensaio de Fenton foi realizado a temperatura ambiente, enquanto que o UV/ $\mathrm{H}_{2} \mathrm{O}_{2}$ e o foto-Fenton foram estudados a temperatura de aproximadamente $37^{\circ} \mathrm{C}$ utilizando a camisa de borossilicato. As condições de estudo para os processos Fenton e foto-Fenton foram de $2800 \mathrm{~mL}$ de efluente, $1200 \mathrm{~mL}$ de $\mathrm{H}_{2} \mathrm{O}_{2}$ e $1,12 \mathrm{~g}$ de $\mathrm{Fe}^{+2}$. Observou-se que no processo Fenton a degradação atingiu 30\% em 120 minutos de reação e para o processo foto-Fenton, no mesmo período, a redução foi de $69 \%$. Com esses resultados, verifica-se a inviabilidade de realizar a degradação pelo processo Fenton, em que o processo foto-Fenton mostrou um melhor resultado pela ação de luz incidente, acelerando o processo de degradação, comprovando assim, resultados na literatura.

Sobretudo, no processo UV-peróxido a taxa de degradação foi de aproximadamente $90 \%$ em 120 minutos de reação como mostrado na Figura 5 abaixo. Este resultado mostra a vantagem do processo UV-peróxido sobre os demais.

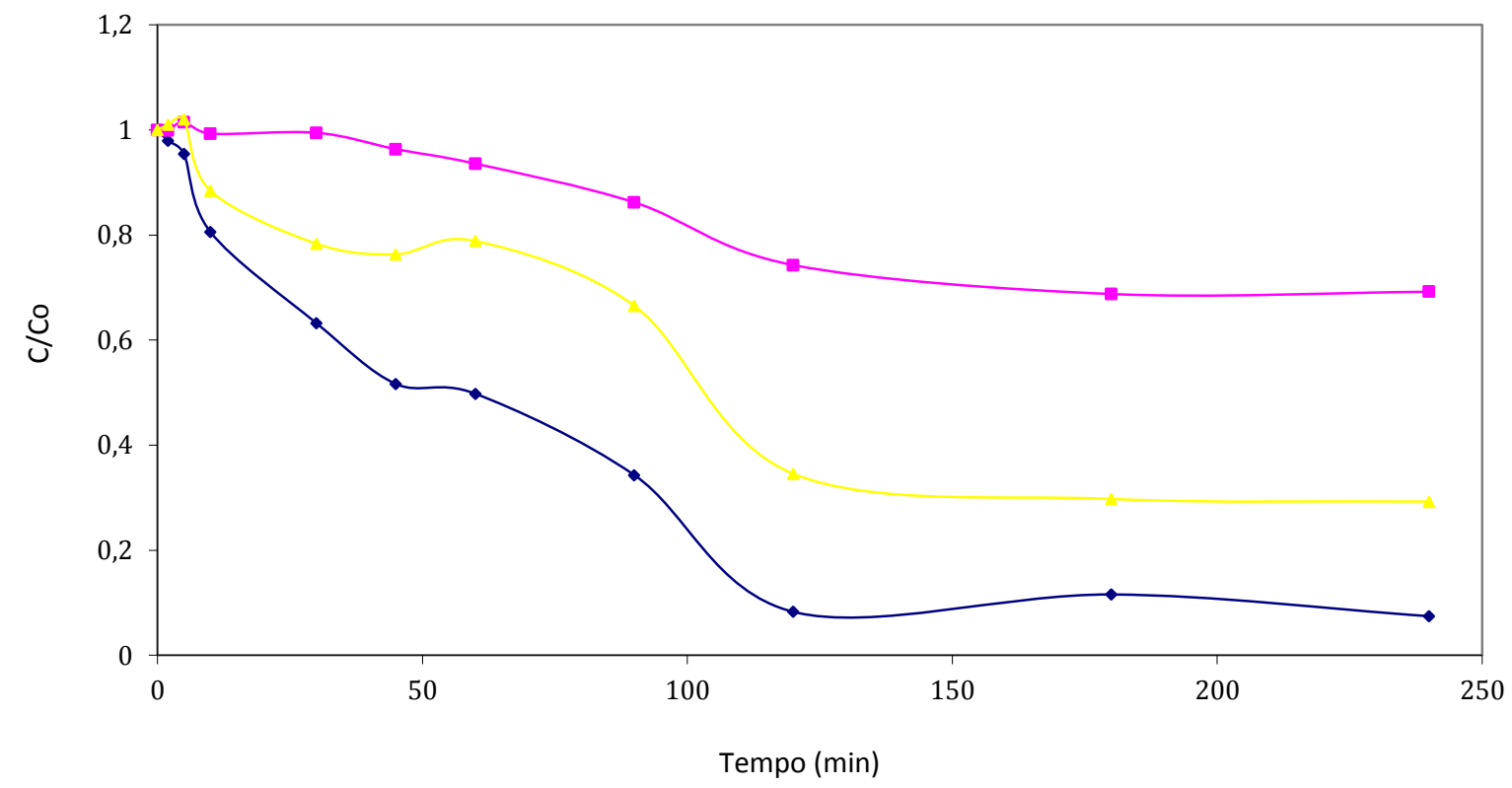

Figura 5: Frações residuais de LCC em UV-peróxido $(\diamond),(\Delta)$ foto-Fenton e $(\square)$ Fenton, $C_{0}=0,8 g / L$, de acordo com o planejamento das Tabelas 1 e 2.

O resultado mostra que há uma diferença de 20 pontos percentuais entre os processos UV-peróxido e foto-Fenton em relação à degradação de matéria orgânica. Portanto, não deve-se 
optar pelo processo foto-Fenton devido a quantidade de ferro utilizado, pois a quantidade de descarte não deve ultrapassar $15 \mathrm{ppm}$, pois representaria um custo maior ao processo e necessitaria de um tratamento posterior para remoção de ferro.

\section{CONCLUSÕES}

De acordo com os resultados experimentais chegou-se às conclusões a seguir:

O processo UV-peróxido apresentou vantagens em relação aos processos de Fenton e foto-Fenton, onde o primeiro mostrou-se bastante satisfatório para degradar o efluente do beneficiamento da castanha de caju, em que na maior parte dos experimentos com altos volumes de efluente, a degradação deste foi superior a $90 \%$.

A degradação fotoquímica do efluente em questão demonstra uma considerável viabilidade técnica, apesar do efeito negativo apresentado pela presença do ferro em considerável quantidade, não permitindo a mineralização total do LCC presente no efluente. A presença do UV é imprescindível, visto que a reação de Fenton apresentou rendimento máximo de $30 \%$, porém, apenas este é insuficiente para promover a degradação do LCC.

O trabalho demonstra a aplicabilidade do processo foto-Fenton na degradação do LCC, com taxas de $69 \%$ de remoção, permitindo um posterior tratamento biológico para remoção dos compostos orgânicos remanescentes.

Recomenda-se para trabalhos futuros um acompanhamento da toxicidade dos compostos gerados durante a reação, pois dependendo do nível de toxicidade que estes compostos apresentem, este efluente pode ter seu tratamento complementado por tratamentos biológicos.

\section{REFERÊNCIAS BIBLIOGRÁFICAS}

1. ANDREOZZI, R.; CAPRIO, V.; INSOLA, A.; MAROTTA, R. Advanced oxidation process (AOP) for water purification and recovery. Catalysis today, n.53, p.51-59, 1999.

2. BAUER, R.; WALDNER, G.; FALLMANN, H.; HAGER, S.; KLARE, M.; KRUTZLER, T.; MALATO, S.; MALETZKY, P. The Photo-Fenton reaction and the TiO2/UV process for wastewater treatment - novel developments. Catalysis today, n.53, p.131-144, 1999.

3. BRAUN, A.M.; JAKOB, L.; OLIVEROS, E.; NASCIMENTO, C. A. O.; up-scaling photochemical reactions, advances in photochemistry, v.18, p236-307, 1993.

4. GIROTO, J.A., Estudo do Processo de Degradação Fotoquímica de Soluções Aquosas de Álcool Polivinílico, 2002, 93f., Escola Politécnica da Universidade de São Paulo, Departamento de Engenharia Química, São Paulo.

5. HARBER, F.; WEISS, J.J.; Proc. Roy. Soc. London Ser A, n. 147, p.332-345, 1934.

6. HENLE, E.S.; LUO, Y.; \& LINN S. Fe2+, Fe3+, and oxygen react with DNA-derived radicals formed during iron-mediated Fenton reactions, Biochemistry, v.35, p. 12212-12219, 1996.

7. OLIVEIRA, R.S.; Degradação Fotoquímica de Gomas a Base de Poliacrilatos em Efluentes Aquosos, Universidade Federal do Rio Grande do Norte, n. 107, p. 10-15, 2003.

8. ROSSETI, G.H.; ALBIZZATI, E.D.; ALFANO, O.M. Decomposition of Formic Acid in a Water 
Solucion Employing the Photo-Fenton Reaction. Industrial Engineering Chemical Research, v.41, p.1436-1444, 2002. 